\title{
PYROLYSIS MODELING OF PVCUSING DISTRIBUTED ACTIVATION ENERGY MODEL- MICRO SCALE TESTING
}

\author{
Abhishek Bhargava $^{\mathrm{a}, \mathrm{b}}$, Patrick van Hees ${ }^{\mathrm{b}}$ \\ ${ }^{\mathrm{a}}$ Danish Institute of Fire and Security Technology, Copenhagen, Denmark \\ ${ }^{\mathrm{b}}$ Lund University, Lund, Sweden
}

\begin{abstract}
Polyvinyl chloride (PVC) is a common thermoplastic whichfinds widespread applications in the construction industryfor usage inceiling linings, flooring materials, electrical cables and roofing materials.Several fire requirements are put on these types of applications. For fire safety engineering and product development, thermo-chemical decomposition modeling of PVC isrequired. The FIRETOOLS project investigates the possibilities to predict real scale fire behavior of building products, content and barriers by means of using material data on successively increasing scale. This paper focuses on the material modeling and studiesthe thermo-chemical decomposition of PVC using Distributed Activation Energy Model (DAEM).
\end{abstract}

Keywords:pyrolysis modeling, fire behavior, Matlab, DAEM

\section{INTRODUCTION}

PVC is one of the major plastics manufactured in the world.Some of the end use applications include usage in window frames, drain pipes, wall coverings, flooring materials and insulation materials for wires and cables.Due to its combustible nature, the reaction to fire propertyof PVC isof great interest, especially at the material level. Pyrolysis modeling enables prediction of mass loss rates at different heating rates using a combination of experimental and simulation technique. The results of these simulations can be used in a CFD code such as fire dynamic simulator (FDS) to perform fire predictions on real scale(Kim \& Dembsey 2012; Stoliarov et al. 2010; McGrattan et al. 2013; Marquis et al. 2012).

\section{THEORETICAL BACKGROUND}

DAEM stands for Distributed Activation Energy Model. It has been used previously to interpret the pyrolysis kinetics of complex multi-component materials such as coal, biomass and sewage sludge(Miura 1995; Miura \& Maki 1998; Soria-Verdugo et al. 2013). These materials are heterogeneous in nature, and when they are exposed to heat, no single reaction determines their thermal decomposition into volatile content; rather the conversion of solid phase into different volatile products is characterized by many parallel occurring reactions. So, the accurate reaction mechanism for such materials may be difficult to ascertain. A similar approach is applied for PVC, whichexhibitstwo-step decomposition mechanism due to the release of hydrogen chloride( $\mathrm{HCl})$ followed by pyrolysis of the remaining residue. For real life applications, PVC is not used as pure material, but several additivesare added into it.For e.g. addition of plasticizers such as aliphatic and aromatic esters improves the flexibility of PVC, a property desirable for usage in electrical cables(Troitzsch 2004). In the scenario, when information related to the on-going chemical reactions due to material interactions upon exposure to heating profile is unavailable for the solid phase, it may be difficult to predict reaction rates, mass loss rates and heat release rate curve. In this work the pyrolysis phenomenon has been modelled using DAEM approach. The main assumptions of the DAEM model are that the reaction mechanism is assumed to consist of infinite set of parallel occurring irreversible single step reactions that have different activation energies and frequency factors. The distribution curve for them is modelled by a Gaussian distribution function (Miura 1995).As per the model equation, the change in total volatiles at time $t$ is given by: 
$1-\frac{\mathrm{v}}{\mathrm{V}^{*}}=\int_{0}^{\omega_{0}} \exp \left(-\mathrm{k}_{\mathrm{b}} \int_{0}^{\mathrm{t}} \mathrm{e}^{\frac{-\mathrm{E}_{\mathrm{a}}}{\mathrm{R}}} \mathrm{dt}\right) * \mathrm{f}\left(\mathrm{E}_{\mathrm{a}}\right) * \mathrm{dE}_{\mathrm{a}}$

where, $V^{*}$ is the effective volatile content, $V$ is the volatile content at temperature $T(K), f\left(E_{a}\right)$ is the distribution curve of the activation energy- $\mathrm{E}_{\mathrm{a}}(\mathrm{kJ} / \mathrm{mol})$ representing differences in the energies of all the reactions and $\mathrm{k}_{0}\left(\mathrm{~s}^{-1}\right)$ is the frequency factor corresponding to the $\mathrm{E}_{\mathrm{a}}$ value, Ris the real gas constant $(8.314 \mathrm{~J} / \mathrm{K} / \mathrm{mol})$.The PVC sample temperature at any time $\mathrm{t}$ is given by

$\mathrm{T}(\mathrm{t})=\mathrm{T}_{\square}+\beta * \mathrm{t}$

Where, $T_{o}$ is the starting temperatureat which no reaction occurs, $\beta(\mathrm{K} / \mathrm{sec})$ is the heating rate and $\mathrm{t}$ is the time (s). Equation (1) can be re-written as:

$1-\frac{\mathrm{v}}{\mathrm{V} *}=\int_{0}^{\mathrm{b}} \varphi\left(\mathrm{E}_{\mathrm{a}} \mathrm{T}\right) * \mathrm{f}\left(\mathrm{E}_{\mathrm{a}}\right) * \mathrm{dE}_{\mathrm{a}}$

Where, $\varphi\left(\mathrm{E}_{\mathrm{a}}, \mathrm{T}\right)=\exp \left(\frac{-\mathrm{K}_{\mathrm{u}}}{\beta} \int_{0}^{\mathrm{T}} \mathrm{e}^{-\mathrm{E}_{\mathrm{a}} / \mathrm{K}} \mathrm{dT}\right)$

Equation (3) can be reduced to the equation (5) by a procedure detailed by(Miura \& Maki 1998; Bhavanam \& Sastry 2015).

$\ln \left(\frac{\beta}{\mathrm{T}^{2}}\right)=\ln \left(\frac{\mathrm{K}_{\mathrm{a}} * \mathrm{~K}}{\mathrm{E}_{\mathrm{a}}}\right)+0.6075-\frac{\mathrm{E}_{\mathrm{a}}}{\mathrm{K}} * \frac{1}{\mathrm{~T}}$

A plot of $\ln \left(\beta / T^{2}\right)$ versus1/T at selected $\mathrm{V} / \mathrm{V}^{*}$ values at three different heating rates is presented in Fig 2. The procedure can be summarized as follows:

- $\quad \mathrm{V} / \mathrm{V}^{*}$ values are measured at three different heating rates using a thermal analyzer.

- At selected values of $\mathrm{V} / \mathrm{V}^{*}$, using the above data a plot of $\ln \left(\beta / T^{2}\right)$ versus $1 / \mathrm{T}$ is made.

- $E_{a}$ and $k_{o}$ values are determined from the slope and intercept of these curves for each conversion level using equation 5 .

- Finally the $f\left(E_{a}\right)$ curve is obtained by differentiating the $V / V^{*} v s E_{a}$ curve and using inbuilt fitting functions in MATLAB.

The $f\left(E_{a}\right)$ curve in such models is assumed to follow Gaussian distribution due to its symmetric nature, however in reality, the kinetic parameters follow significantly different distribution having considerable asymmetry. The $f\left(E_{a}\right)$ curve, in such cases may be described by other statistical distribution functions such as Weibull and Logistic functions(Lakshmanan \& White 1994; Cai et al. 2014). Table 1 shows the distribution function and different characteristic parameters defining the $\mathrm{f}\left(\mathrm{E}_{\mathrm{a}}\right)$ curve. The main issue however, is the range of applicability of such model equations. Often several materials decompose in a two-step mechanism, exhibiting a shoulder peak and this was evident in the results obtained for PVC, see figure 1.

Table 1 Statistical distribution function to describe chemical kinetic parameters for usage in DAEM model

\begin{tabular}{|l|l|l|l|}
\hline S.No & $\mathrm{f}(\mathrm{Ea})$ & Distribution function & Parameters \\
\hline 1. & Gaussian & $\frac{1}{\sqrt{2 \pi}} \exp \left[-\frac{E_{a}-E_{a \mathrm{u}}}{2 \sigma^{2}}\right]$ & $\begin{array}{l}\text { Mean Activation Energy }-E_{a \mathrm{u}} \\
\text { Standard Deviation- } \sigma\end{array}$ \\
\hline
\end{tabular}

\section{COMPUTATIONAL CHALLENGES AND SOLUTION TECHNIQUES}

The main computational hurdle in the DAEM model is that there is no closed form solution to this model. Equation 1 is a double integral equation and has inner dT integral and an outer $\mathrm{dE}_{\mathrm{a}}$ integral.(Cai et al. 2014) have divided the solution approaches to this model in two main categories 
namely, distribution free methods and distribution fitting methods. In this paper, the Miura Maki integral method (a form of distribution free method)(Miura \& Maki 1998; Soria-Verdugo et al. 2013) has been employed to find the solution to Equation 1.

\section{EXPERIMENTAL}

The experimental data was provided by VTT Technical Research Centre, Finland and published in (Matala \& Hostikka 2011). For the experiments, a simultaneous thermal analyzer NETZSCH STA 449 was used in both air and nitrogen atmosphere for the measurement of mass changes. The samples $(\approx 20 \mathrm{mg})$ were placed in alumina $\left(\mathrm{Al}_{2} \mathrm{O}_{3}\right)$ crucibles and subjected to linear heating profiles $(2 / 5 / 10 / 20 \mathrm{Kelvin} / \mathrm{min})$ at four different heating rates in the TGA apparatus.

\section{RESULTS AND DISCUSSIONS}

\subsection{Thermal decomposition in inert and air atmosphere - TGA and DTG curves}

Fig.1 shows the TGA and DTG curves of the PVC samples as recorded experimentally in ambient and inert conditions. The onset of thermal decomposition of PVC starts at about $500 \mathrm{~K}$ in air and nitrogen.
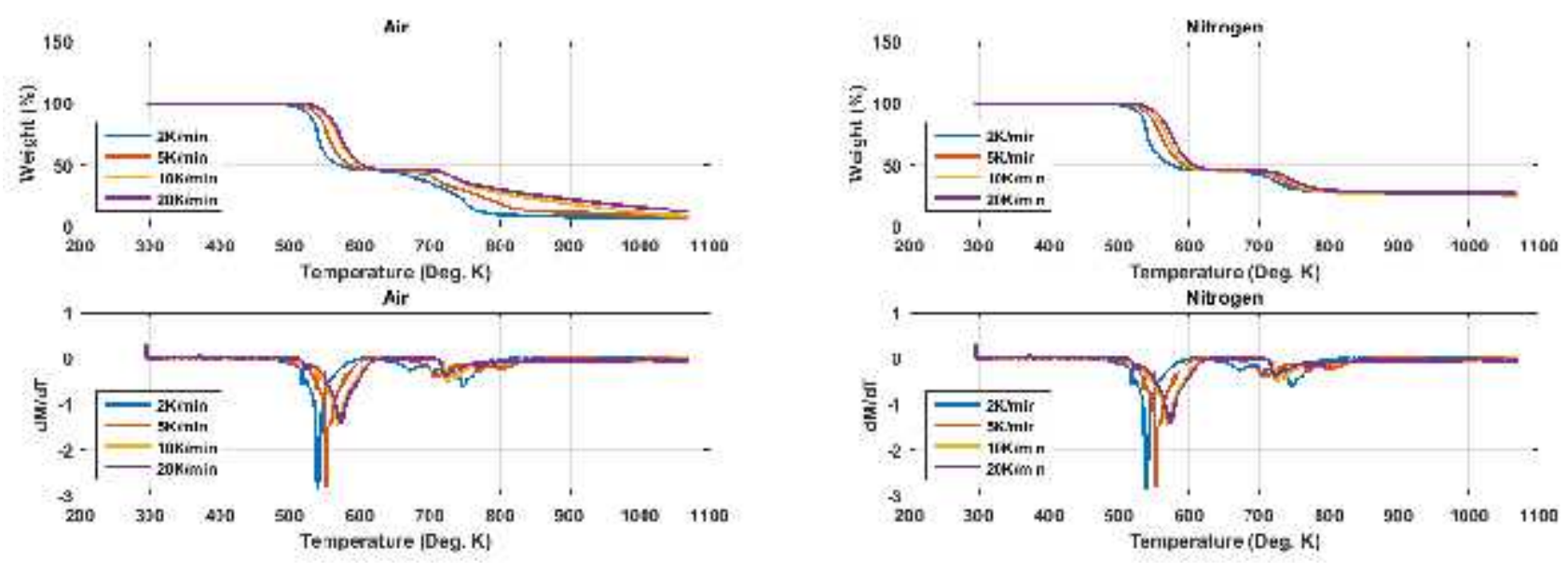

Fig.1 TGA and DTG curves for pure PVC in air and nitrogen at different heating rates

The decomposition occurs in a two-step reaction as evident from the TGA curve(shoulder) and two different peaks recorded in the DTG curve. The sample lost about 54\% weightin the first reaction in both air and nitrogen. The first reaction pertains to the release of hydrogen chloride $(\mathrm{HCl})$ and is termed as de-hydro-chlorination (Huggett \& Levin 1987; Matala \& Hostikka 2011). The decomposition mechanism issensitive to the applied heating rate and shifts towards the right with the increasing heating rate i.e. from $5 \mathrm{~K} / \mathrm{min}$ to $20 \mathrm{~K} / \mathrm{min}$. Also, in ambient atmosphere oxidation reactions occur and further complicate the shape of the mass loss curve. The residual weight in ambient and nitrogen environment is $7-11.5 \%$ and $25.5-27 \%$ respectively. Due to space constraints, the DAEM model has been applied to the experiments performed under nitrogen atmosphere only, and the two reaction steps have been characterized separately using DAEM parameters.

\subsection{Arrhenius fittings for two different reaction steps}

Figure 2 shows linear fit of Arrhenius plots for PVC samples. It is a graph between $\ln \left(\beta / \mathrm{T}^{\wedge} 2\right)$ versus $1 / \mathrm{T}$ for selected conversion levels for each reaction (see equation 5).For reaction 1 , the plots are straight lines, while for the second reaction due to the onset of gasification; the fittings are not good in the beginning and at the end conversion levels. When the reaction is steady, i.e. when the conversion levelV/ $\mathrm{V}^{*}$ is between $0.55-0.71$, the fittings follow straight lines. 

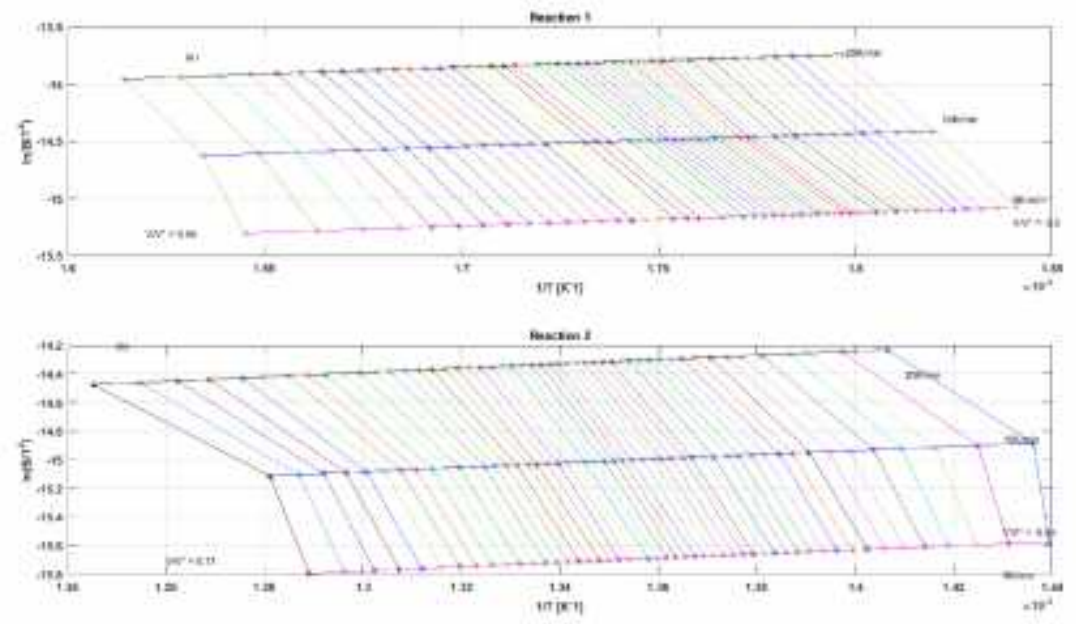

Figure 2 Arrhenius plot of $\ln \left(\beta / \mathrm{T}^{\wedge} 2\right)$ versus $1 / \mathrm{T}$ at selected $\mathrm{V} / \mathrm{V}^{*}$ values for $\mathrm{PVC}$ for reaction 1 and 2

\subsection{Kinetic parameters and their distribution curves}

Fig. 3 shows the frequency distribution curve of the activation energy $\left(\mathrm{E}_{\mathrm{a}}\right)$ for both the reactions. The values are distributed over the range $228-351 \mathrm{~kJ} / \mathrm{mol}$ for the first one, while for the second reaction the values are distributed over the range $218-405 \mathrm{~kJ} / \mathrm{mol}$.
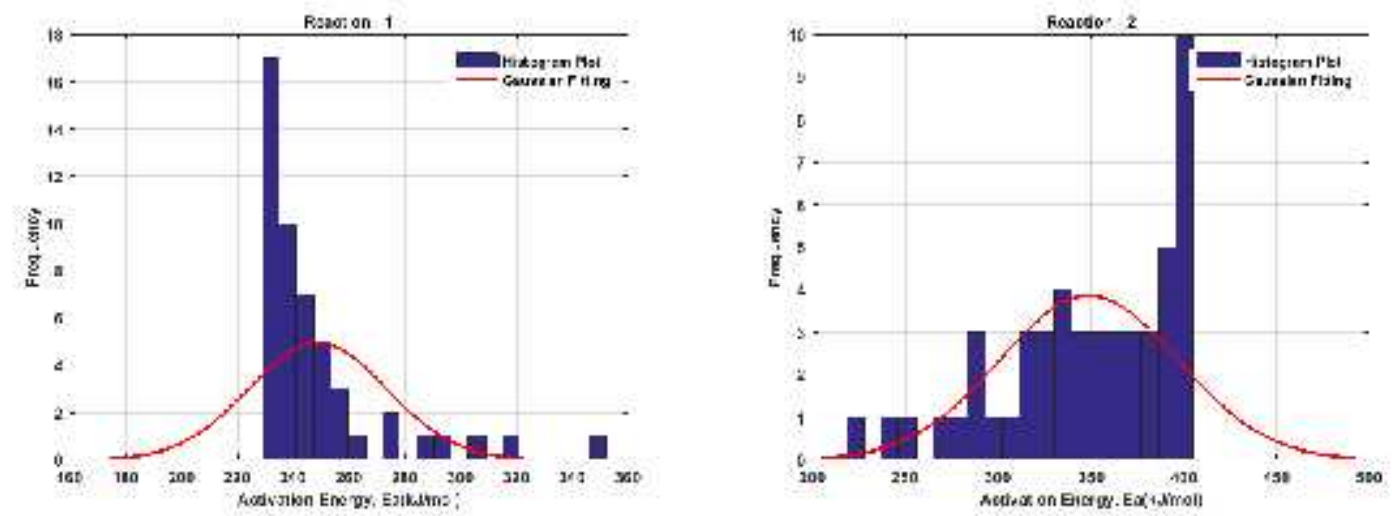

Fig.3 Frequency distribution curve of activation energy for reaction 1 and reaction 2 for PVC in nitrogen

Table 2 shows a summary of the chemical kinetic parameters obtained by the solution of DAEM model.

Table 2 Summary of Arrhenius parameters computed for PVC with DAEM model

\begin{tabular}{|c|c|c|c|}
\hline Reaction 1 & Mean & Standard Deviation & Range \\
\hline $\mathrm{E}_{\mathrm{a}}(\mathrm{kJ} / \mathrm{mol})$ & 248.7 & 10.0 & $228.8-351.8$ \\
\hline $\mathrm{k}_{0}\left(\mathrm{~s}^{-1}\right)$ & $3.6 \times 10^{20}$ & $2.5 \times 10^{21}$ & $2.2 \times 10^{13}-1.8 \times 10^{22}$ \\
\hline Reaction 2 & & & \\
\hline $\mathrm{E}_{\mathrm{a}}(\mathrm{kJ} / \mathrm{mol})$ & 348.9 & 48.1 & $218.5-404.8$ \\
\hline $\mathrm{k}_{\mathrm{o}}\left(\mathrm{s}^{-1}\right)$ & $7.7 \times 10^{19}$ & $1.5 \times 10^{20}$ & $2.3 \times 10^{6}-5.2 \times 10^{20}$ \\
\hline
\end{tabular}

\subsection{Experimental Results VsNumerical Simulations}

The model simulations have been performed for all the heating rates $(5 / 10 / 20 \mathrm{~K} / \mathrm{min})$ and for each conversion level by the solution of the non-linear equation using numerical method (bisection method). 

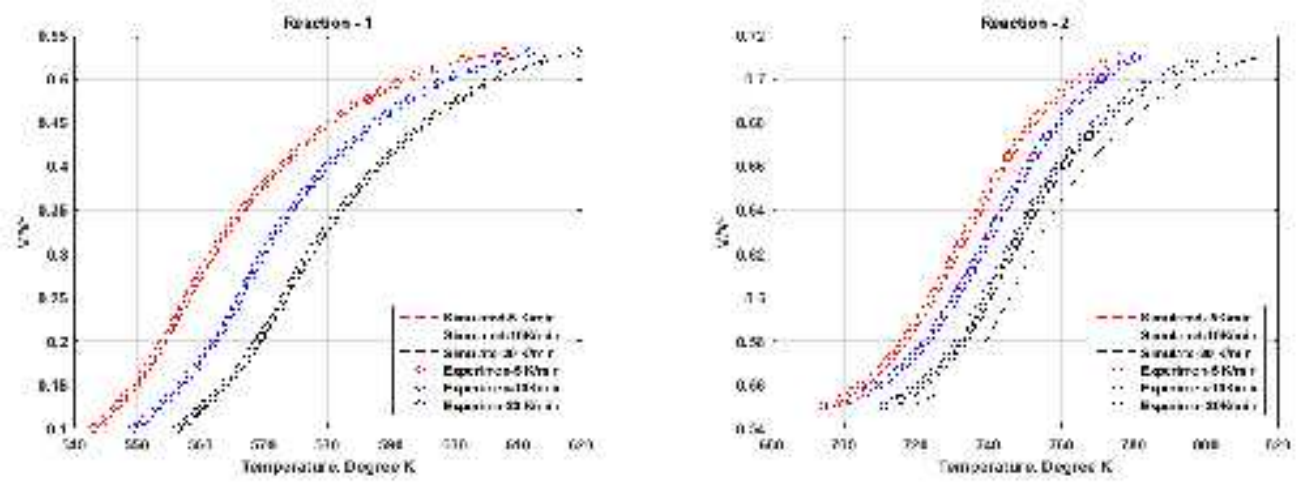

Fig,4 Model validation curve - experimental data and numerical simulations

For reaction 1 the simulations match experimental data very closely. The average percentage error is less than 0.25 percent;however for the reaction 2 , the simulations show a slight over-prediction error. The percentage error is less than 2.3 percent.

\subsection{Prediction of mass loss rates (MLRs) at high linear heating rates}
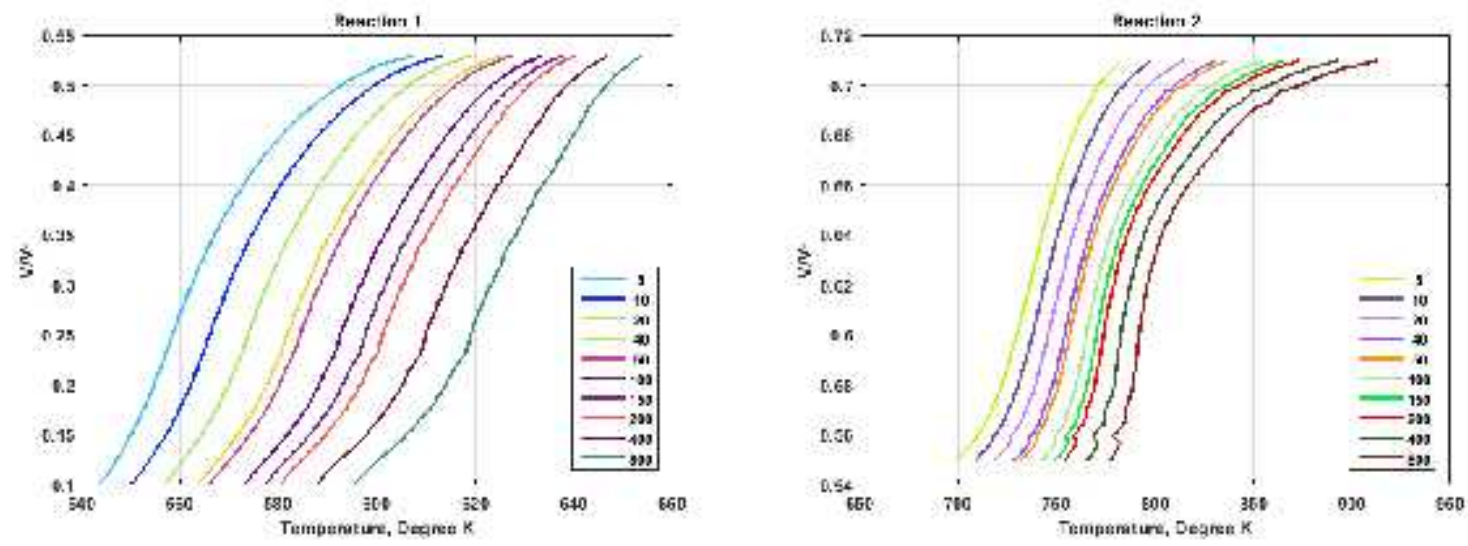

Fig.5 Predicted MLRs for reaction 1 and 2 for PVC in nitrogenat high heating rates ( $\beta$ in $\mathrm{K} / \mathrm{min}$ )

Fig.5shows predicted mass loss rate (MLRs) for PVC at increasing heating rates (up to $800 \mathrm{~K} / \mathrm{min}$ ) in nitrogen atmosphere. This is obtained by numerical solution of equation 14 for desired heating rate and computed chemical kinetic parameters retrieved using the slopes and intercepts of the Arrhenius plots (Figure 2). Experiments using thermal analyzers at high heating rates are difficult to perform due to lack of equipment availability. Although, many simultaneous thermal analyzers (STAs) can obtain a heating rate of 100 degrees $\mathrm{K} / \mathrm{min}$ but there are several challenges associated with the experimentation at high temperatures. Simulations are a cost effective way of predicting material behavior under experimentally difficult conditions.

\section{CONCLUSIONS}

For fire simulations, very detailed chemical reactions mechanisms may not be of much significance due to the challenges they pose in the implementation of CFD codes such as fire dynamic simulator (FDS).In this paper,the DAEM method uses the Miura Maki integral approach to retrieve chemical kinetic parameters and predict mass loss rates curvesfor PVC under inert atmosphere at high linear heating rates. The computed kinetic parameters are distributed over a significantrange (modelled by a Gaussian bell curve) for both reactions. The results of these predictions can be used as input parameter in fire simulations of building products but further validation and experience with the method is needed. The model calculations may later be applicable to a variety of building products such as flooring materials, window frames and drainage pipes in combination with advanced flame spread calculations. With the development of in house computer code, the calculation process is fast and experimental effort reduced. 


\section{ACKNOWLEDGMENTS}

This work was supported by the funding received from European Union Seventh Framework Program (FP7/2007-2013) under grant agreement $n^{\circ} 316991$ for the project FIRETOOLS. The authors would like to thank Dr. Anna Matala (VTT Technical Research Centre, Finland) for providing experimental thermo-gravimetricdata for the model validation work.

\section{REFERENCES}

Bhavanam, A. \& Sastry, R.C., 2015. Kinetic study of solid waste pyrolysis using distributed activation energy model. Bioresource Technology, 178, pp.126-131.

Cai, J., Wu, W. \& Liu, R., 2014. An overview of distributed activation energy model and its application in the pyrolysis of lignocellulosic biomass. Renewable and Sustainable Energy Reviews, 36, pp.236-246.

Huggett, C. \& Levin, B., 1987. Toxicity of the pyrolysis and combustion products of poly (vinyl chlorides): a literature assessment. Fire and materials, II(January), pp.131-142.

Kim, M.E. \& Dembsey, N., 2012. Engineering Guide for Estimating Material Pyrolysis Properties for Fire Modeling,

Lakshmanan, C. \& White, N., 1994. A new distributed activation energy model using Weibull distribution for the representation of complex kinetics. Energy \& fuels, 31(5), pp.1158-1167.

Marquis, D.M., Pavageau, M. \& Guillaume, E., 2012. Multi-scale simulations of fire growth on a sandwich composite structure. Journal of Fire Sciences, 31(1), pp.3-34.

Matala, A. \& Hostikka, S., 2011. Pyrolysis modelling of PVC cable materials. In Fire Safety Science. pp. 917-930.

McGrattan, K. et al., 2013. Fire Dynamics Dimulator (version 5), Technical reference guide. Volum1: Mathematical Model,

Miura, K., 1995. A New and Simple Method to Estimate $\mathrm{f}(\mathrm{E})$ and $\mathrm{ko}(\mathrm{E})$ in the Distributed Activation Energy Model from Three Sets of Experimental Data Kouichi. Energy \& Fuels, 9(4), pp.302-307.

Miura, K. \& Maki, T., 1998. A Simple Method for Estimating $\mathrm{f}(\mathrm{E})$ and $\mathrm{k} 0(\mathrm{E})$ in the Distributed Activation Energy Model. Energy \& Fuels, (12), pp.864-869.

Soria-Verdugo, A. et al., 2013. Analysis of biomass and sewage sludge devolatilization using the distributed activation energy model. Energy Conversion and Management, 65, pp.239-244.

Stoliarov, S.I. et al., 2010. Prediction of the burning rates of charring polymers. Combustion and Flame, 157(11), pp.2024-2034.

Troitzsch, J., 2004. Plastics Flammability Handbook - Principles, Regulations, Testing, and Approval (3rd Edition), Hanser Publishers. 